\title{
The Impact of Vibroacoustic Therapy on Subjective Perception of University Students - Mixed Design Pilot Study
}

\author{
Zdeněk Vilímek $^{1, *}$, Jiří Kantor $^{1,2}$, Jana Kořínková $^{3}$ \\ ${ }^{1}$ Institute of Special Education Studies, Faculty of Education, Palacky University, Olomouc, 77900, Czech Republic \\ ${ }^{2}$ The Center of Evidence-Based Education and Arts Therapies, Faculty of Education, Palacky University, Olomouc, 77900, Czech \\ Republic \\ ${ }^{3}$ Institute of Foreign Languages, Faculty of Education, Palacky University, Olomouc, 77900, Czech Republic
}

Received December 2, 2020; Revised May 20, 2021; Accepted June 6, 2021

\section{Cite This Paper in the following Citation Styles}

(a): [1] Zdeněk Vilímek, Jiři Kantor, Jana Kořinková , "The Impact of Vibroacoustic Therapy on Subjective Perception of University Students - Mixed Design Pilot Study," Universal Journal of Educational Research, Vol. 9, No. 7, pp. 1409 1420, 2021. DOI: 10.13189/ujer.2021.090707.

(b): Zdeněk Vilímek, Jiř́ Kantor, Jana Kořinková (2021). The Impact of Vibroacoustic Therapy on Subjective Perception of University Students - Mixed Design Pilot Study. Universal Journal of Educational Research, 9(7), 1409 1420. DOI: 10.13189/ujer.2021.090707.

Copyright $\mathrm{C} 2021$ by authors, all rights reserved. Authors agree that this article remains permanently open access under the terms of the Creative Commons Attribution License 4.0 International License

\begin{abstract}
Vibroacoustic therapy (VAT) is a modern therapeutic approach that combines low-frequency sound vibrations with listening to music. One of the new technologies developed for VAT is Vibrobed, a vibrating bed intended for rehabilitation. The aim of the present pilot study with mixed methods research design is to explore the impact of a Vibrobed course using an original listening program called The Elements 2019 on the subjective experience of study participants, specifically on their physical perception, emotions and mental associations. The study involved 30 university students who underwent three sessions on the Vibrobed. The research data were obtained through a newly-designed questionnaire (processed by means of descriptive statistics and paired t-test) and through qualitative interviews (processed by means of inductive content analysis). The study results seem to indicate that a session on the Vibrobed may increase the level of perceived physical well-being and relaxation, and that it has potential for psychosomatic regulation of the human body. This could be utilized in coping with acute stress and has a positive influence on the quality of life of students in various educational institutions, for instance in the form of preventive programmes at universities. Due to the limitations of the current study, however, it is yet necessary to verify the potential use of the vibroacoustic program
\end{abstract}

through further research, ideally using an experimental design.

Keywords Vibroacoustic Therapy, Vibroacoustic Treatment, Music, Subjective Perception, Physical Perception

\section{Introduction}

The origins of vibroacoustic therapy (VAT) date back to the 1980s, when the first prototype of a vibroacoustic unit was designed by the Norwegian teacher Olav Skille. VAT is defined as "the use of sinusoidal, low-frequency sound waves in the range of $30-120 \mathrm{~Hz}$, which are mixed with music and intended for therapeutic purposes $[1, p$. 36]. Three main elements are typical for most methods used in VAT: low-frequency sound vibrations, listening to clients' preferred music and a therapeutic interaction [2].

In the course of VAT history, a number of vibroacoustic technologies have been designed. These differ primarily in the characteristics of the low-frequency sounds, employed materials and construction, localization of the low-frequency sound on various areas of the human body, etc. VAT technologies available on the current 
market include, for instance, the physio-acoustic chair Next Wave, the vibroacoustic bed Sound Oasis VTS1000, the Transducers Mattress Multivib 10, and many others [3]. Among the latest VAT innovations belongs a rehabilitation vibration bed, VIBROBED ${ }^{\circledR}$ (Figure 1), constructed by Czech designers Zdeněk Vilímek and Petr Švarc in 2016. One of the unique features of the Vibrobed is a close interaction between the low-frequency sound and the music listened to by the client; these are synchronically mixed to form a complete unified audio composition and transmitted to four zones of the body schema (calves, thighs, upper back area and low back area). The Vibrobed has its own 4-channel amplifier, music player and low-frequency sound generator with various sinusoidal signal settings that can be selected according to clients' individual needs. Another specific feature of the Vibrobed technology is its wooden resonant diaphragm (as opposed to the traditional and more comfortable padded vibration-damping one) equipped with eight special low-frequency sound wave exciters (instead of traditional subwoofers).

The innovative Vibrobed technology uses sequential dosing of sound (pulse and panoramic), and various modulations of low-frequency waves in combination with sound and music stimuli. Unlike the traditional solution of a continuous low-frequency dosing, where one of the contraindications is the supersaturation syndrome, a sequential dosing offers a safer method. As the vibrations are perceived throughout the whole body, this new type of stimulation seems to be more natural for the human organism [4].

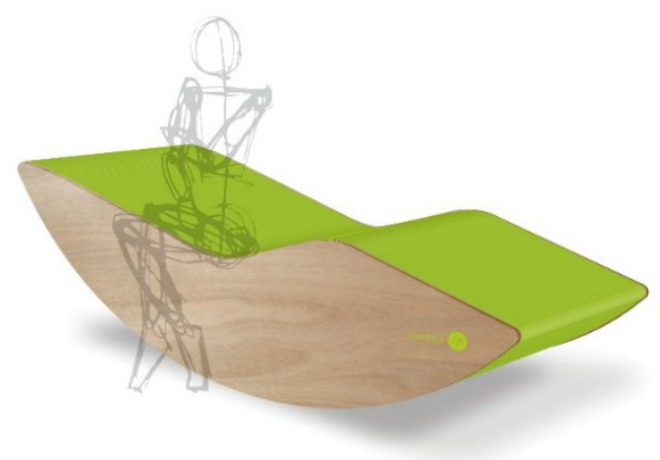

Figure 1. Rehabilitation vibrating bed VIBROBED ${ }^{\circledR}$ (authors’ archive, 2018)

According to Skille [5], the effects of VAT fall into the following three categories: a) spasmolytic and muscle relaxation effect, b) increased blood circulation, and c) effect on the vegetative system manifested by excitation of the sympathetic or parasympathetic division of the autonomic nervous system. Although the current knowledge of the therapeutic possibilities of VAT has been based primarily on empirical experience, some research studies also attempted to objectively verify the effect of the low-frequency sound on the human body. The main areas of VAT indication include painful conditions [6], cerebral palsy [7], Parkinson disease [8], self-harm [9], and others.

Some studies have shown the effect of VAT in patients with different types of health problems. They focused on, for instance, heart rate variability $[10,11]$, galvanic skin response [10], and blood pressure and pulse rate [12, 13]. These research studies, like the present one, made use of questionnaires, self-assessment scales and interviews [14, $15]$.

Other researchers focused on the influence of VAT on the general population. Wigram [16-18] published three studies with the following aims:

- To evaluate the perception of low-frequency tone vibrations in the human body [16]. The participants were exposed to low sinusoidal sounds in the range of 20-70 Hz and reported which part of their body felt the highest sensation at specific frequencies.

- To measure how VAT influences mood and physiological responses (blood pressure and heart rate), compared to control sessions with music and no VAT session at all [17].

- To measure the effect of amplitude modulation of the pulsed sinusoidal low frequency tones on blood pressure, heart rate and mood [18].

Other authors found out that VAT increased levels of relaxation and mental imagery and reduced negative moods over a sequence of eight sessions in professional orchestra musicians [19]. According to Rüütel [12] VAT, compared to music alone and silence, may have a wider influence on one's subjective feeling of health and comfort. Ahonen et al. [20] focused on university students and university staff and found out that sessions on a physioacoustic chair had an effect on the overall well-being in their daily lives, including both physical and emotional relaxation. The participants described less pain, tension and stress, increased inner peace and self-reflection, increased concentration and alertness, emotional enrichment, space to re-charge, and other.

The relatively low number of studies exploring the potential of VAT in a typical population inspired the authors to plan and realize the present pilot study. Its aim was to explore the influence of the Vibrobed, a new vibroacoustic technology, on the subjective perception in the population of university students. University students belong to potential VAT beneficiaries in whom vibroacoustic program may positively influence and prevent some specific risks, such as acute stress [21].

\section{Materials and Methods}

The present mixed research study with parallel design used an observational design (without a control group) for the quantitative part, and a phenomenologically oriented design based on inductive content analysis for the qualitative part. The objectives of the study were: 
- To determine whether a program on the Vibrobed affects the subjective perception of the physical well-being of participants.

- To identify the most significant changes in participants' physical perception during the Vibrobed session.

- To find out which emotions participants experienced during the Vibrobed session.

- To find out what mental associations occur in participants over the course of the Vibrobed session.

The individual areas of subjective perception were determined for the following reasons:

- Physical well-being and the level of alertness are related to the expected relaxation effect of the Vibrobed program, while physical well-being is closely linked to quality of life.

- Emotional well-being is essential in terms of VAT preferences and the popularity of this type of therapeutic program.

- Analysis of mental associations can help to interpret the obtained findings.

\subsection{Research Experiment}

The pilot study was carried out between March and
May 2018 at the Faculty of Education, Palacký University in Olomouc. 30 students participated in three identical research experiments involving the Vibrobed program. For each participant, it took place once a week for 20 minutes, over three consecutive weeks, using the low-frequency sound listening program called The Elements 2019 (Figure 2). The original music was composed for this recording. This recording features four 5-minute compositions which purposefully influence the biorhythmic pulsation - from the resting, through the exited, to the deeply relaxed state.

Prior to the Vibrobed sessions, all participants were informed about the course of the pilot study, about the research methodology and they were asked to sign an informed consent which had been approved by the Ethics Committee of the Faculty of Education, Palacký University. The research experiment procedure was standardised for all the participants. Before the commencement of each experiment session, participants were instructed to lie down on their backs, and asked to could close their eyes, and use a blanket and/or a pillow, if they wished. The experiment took place in a specially adapted room at the Faculty of Education, Palacký University (a soundproofed room guaranteeing privacy, with insulation between the bed and the floor).

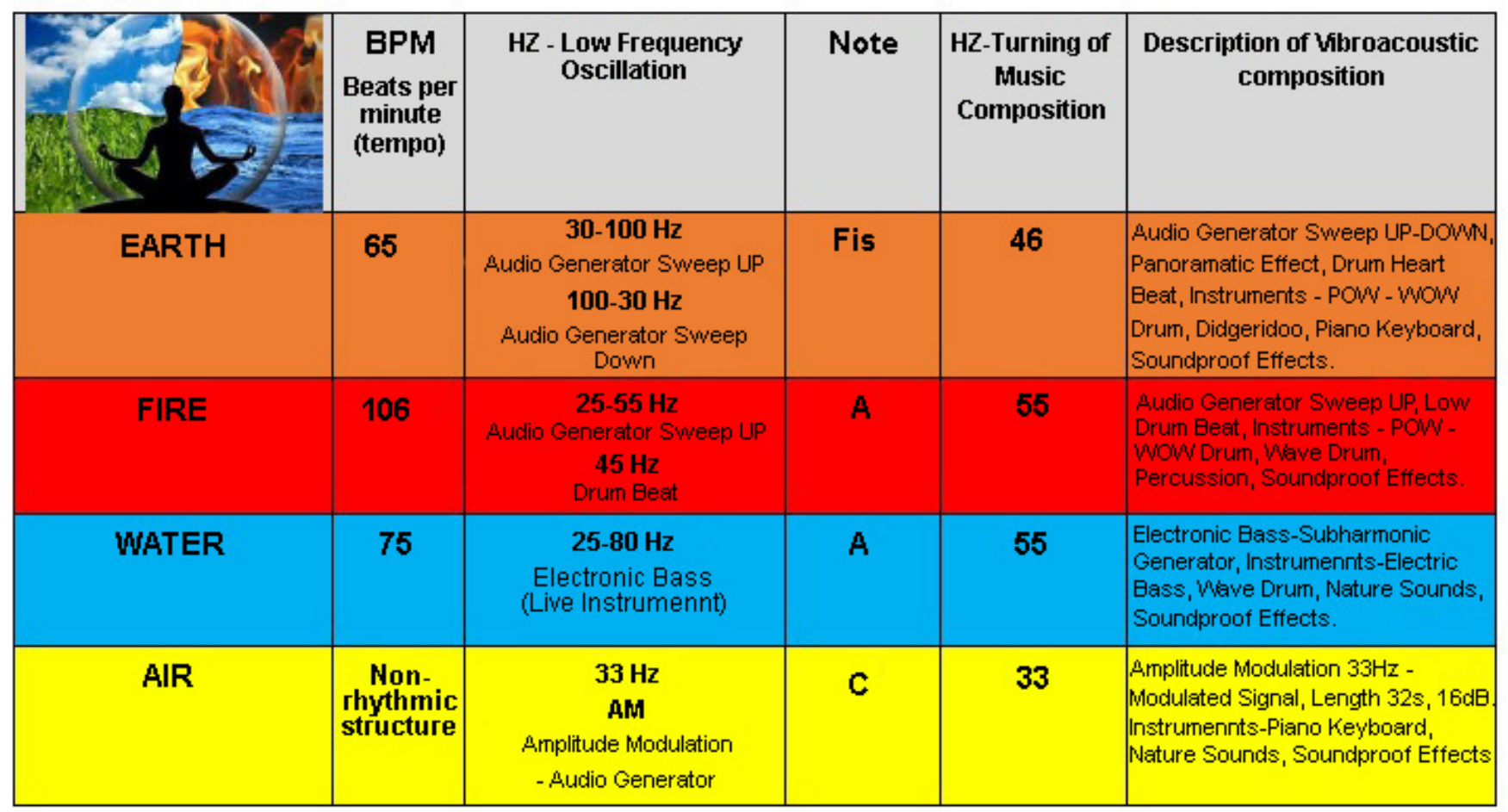

Figure 2. Description of the original vibroacoustic listening program The Elements 2019 


\subsection{Data Collection and Data Analysis}

The research data were collected using an initial anamnestic protocol, a newly-designed questionnaire and qualitative interviews. The anamnestic protocol was completed by the participants only once, before the first experiment, as its purpose was to record their essential personal details (age, gender, basic health date, etc.)

The questionnaire was completed by the participants prior each experiment session in its abbreviated version, and in its full version after the session ended (see Appendix A). The questionnaire used numeric rating scales $(0-10)$ for the evaluation of participants' physical well-being, as well as items designed to obtain additional information regarding participants' physical perceptions, emotions, alertness level and musical preferences. To process the numeric items (focused on physical well-being), arithmetic means of the differences from all pre-tests and post-tests were calculated for all the participants, and these were statistically verified by a paired t-test at the significance level of $p=0.05$. The remaining items of the questionnaire were evaluated solely by means of descriptive statistics methods. The statistical analysis was carried out using the STATISTICA 12 data analysis program.

Each research experiment session was followed by a qualitative interview, which invited the participants to describe their experience during the Vibrobed session. The obtained qualitative data were evaluated using inductive content analysis, which is "a research method for subjective interpretation of textual data content through the process of systematic classification and identification of topics and patterns" [22, p. 278]. The process of inductive analysis comprised several steps which enabled the creation of a classification system ranging from the smallest data units (codes) to the most general data units (categories labelling the individual topics). It was thus possible to organize the related codes into common subcategories and categories, while the codes belonging (in terms of their content) to more than one category could be coded repeatedly [23]. The individual codes were also commented on in the context of the information obtained from the individual participants.

\subsection{Research Sample}

The study involved 30 participants selected from a group of students of the Faculty of Education, Palacký University in Olomouc. The inclusion criteria were the following: 1.voluntary participation, 2. good health (absence of known contradictions to VAT, disability or illness), 3. aged between 18-40, 4. absence of acute, long-term illness or psychiatric condition, 5. no alcohol and non-alcohol drug intake one day prior the experiment.

The selection of participants was based on deliberate sampling; all participants were full-time students of the
Special pedagogy study program at Palacký University in Olomouc. Their inclusion in the study was conditioned by signing an informed consent. This study followed the principles of the Declaration of Helsinki.

Research sample characteristics:

- The sample included 28 females and 2 males.

- The age distribution was the following: 5 participants aged 15-20, 55 participants aged 21- 25, one participant aged 27-30 and one participant aged over 30.

- Participants' stress load over the recent weeks was categorized into five degrees (none, mild, medium, severe and extreme). 7 participants reported no stress, 12 reported mild stress and 10 moderate stress.

- 11 participants reported that they actively played a musical instrument.

- Participants' preferred music genres included popular music (19 participants), rock music (11 participants), alternative/world music (5 participants), hip-hop and rap (4 participants) and jazz (3 participants). Most participants stated a combination of several music genres.

\section{Results}

The results of the quantitative part of the study concern the influence of the Vibrobed program on participants' subjective perception of physical well-being, physical changes, emotional experience, level of alertness and mental associations. To determine the impact of the Vibrobed on the subjective perception of well-being, the first and third measurements were statistically processed. Due to the absence of one measurement (one of the participants reported illness), the statistical analysis was performed on the final number of 29 probands. A statistically significant improvement in the subjective perception of well-being after the Vibrobed session was measured at a significance level of $p=0.05$ (Table 1). The comparison of values between the first and the third measurements shows a trend for a reduction of the measured effect with the increasing number of sessions.

Table 1. Results of the statistical analysis of the perception of physical well-being

\begin{tabular}{ccccc}
\hline Variable & $\begin{array}{c}\text { Average } \\
\text { (differences } \\
\text { between pretests } \\
\text { and post-tests) }\end{array}$ & $\begin{array}{c}\text { Standard } \\
\text { deviation }\end{array}$ & T & P \\
\hline $\begin{array}{c}\text { Before 1. } \\
\text { session }\end{array}$ & 6.966 & 1.401 & - & - \\
\hline $\begin{array}{c}\text { After 1. } \\
\text { session }\end{array}$ & 8.172 & 1.311 & -5.833 & $<0.001$ \\
\hline $\begin{array}{c}\text { Before 3. } \\
\text { session }\end{array}$ & 7.966 & 1.052 & - & - \\
\hline $\begin{array}{c}\text { After 3. } \\
\text { session }\end{array}$ & 8.276 & 1.032 & -2.197 & 0.036 \\
\hline
\end{tabular}

The remaining items of the questionnaire were 
processed using descriptive statistics. Table 2 compares the data from all three experiments regarding the perceived changes in participants' muscle tonus, tonus along the spinal cord, and other specific changes:

- Muscle tonus was assessed on a seven-point scale. Most participants reported muscle relaxation during all three measurements, except for one participant who described a slight increase of muscle tension due to a disturbing effect of vibrations in the final part of the recording.

- The changes in the perception in the area along the participants' spinal cord (measured on a three-point scale) were less pronounced compared to those related to the muscle tonus. Most participants did not identify any changes, while part of the sample reported relaxation.

- Other bodily sensations were reported through nominal items. Most frequently represented were feelings of energy flow, changes of breathing rhythm, feeling cold (less often hot), feeling heartbeat, feeling heavy, and breaking into sweat (rarely).
Table 3 presents types of emotions experienced by the study participants during the Vibrobed sessions. The list of items related to emotions was compiled based on observations and reflections reported by several sources [24-28]. All of these were nominal value items. The respondents were asked to indicate whether the listed types of emotions occurred during each session, regardless of their intensity or duration. Overall, emotions with positive valence prevailed (especially joy and optimism). Emotions with negative valence were reported with significantly lower frequencies or not at all. The emotions of sadness, rejection, boredom, anger, regret and fury were reported by not more than two participants at each session, and disgust was not reported at all.

When comparing all individual measurements, it is possible to observe increasing and decreasing tendencies related to some of the listed emotions. An increasing tendency was observed with joy, optimism and confidence, while a decreasing tendency was typical for expectations, curiosity and surprise.

Table 2. Changes in muscle tonus, tonus along the spinal cord, and other specific changes - absolute frequency in the group of 29 probands

\begin{tabular}{|c|c|c|c|c|}
\hline CATEGORY & SUBCATEGORY (intensity or type) & Meeting 1 & Meeting 2 & Meeting 3 \\
\hline Total perception of the muscle tonus & considerable release of muscle tension & 4 & 1 & 5 \\
\hline \multirow[t]{7}{*}{ (dominant feeling after listening) } & moderate release of muscle tension & 12 & 12 & 8 \\
\hline & slight release of muscle tension & 10 & 11 & 10 \\
\hline & feeling cold & 10 & 13 & 13 \\
\hline & unchanged & 2 & 4 & 6 \\
\hline & slight increase in muscle tension & 1 & 1 & 0 \\
\hline & moderate increase in muscle tension & 0 & 0 & 0 \\
\hline & high increase in muscle tension & 0 & 0 & 0 \\
\hline \multirow[t]{3}{*}{ Tension in the area of the spine cord } & release & 12 & 10 & 10 \\
\hline & unchanged & 15 & 18 & 18 \\
\hline & increase tension & 2 & 1 & 0 \\
\hline \multirow[t]{6}{*}{ Other types of changes } & feeling energy flow & 28 & 21 & 18 \\
\hline & changes of breathing rhythm & 18 & 13 & 14 \\
\hline & feeling heartbeat & 9 & 3 & 4 \\
\hline & feeling warm & 8 & 5 & 8 \\
\hline & feeling heavy & 6 & 6 & 6 \\
\hline & Sweating & 1 & 0 & 0 \\
\hline
\end{tabular}


Table 3. Types of emotions experienced by the participants during the Vibrobed sessions

\begin{tabular}{|c|c|c|c|}
\hline Types of emotions & I1 & $\mathbf{I 2}$ & I3 \\
\hline expectation & 24 & 16 & 17 \\
\hline curiosity & 23 & 10 & 13 \\
\hline surprise & 22 & 7 & 10 \\
\hline joy & 17 & 21 & 21 \\
\hline optimism & 16 & 21 & 24 \\
\hline confidence & 12 & 17 & 19 \\
\hline $\begin{array}{c}\text { amazement } \\
\text { (euphoria) }\end{array}$ & 9 & 7 & 7 \\
\hline respect & 7 & 4 & 9 \\
\hline love & 5 & 4 & 9 \\
\hline fear & 5 & 4 & 4 \\
\hline ecstasy & 3 & 1 & 1 \\
\hline annoyance & 2 & 4 & 3 \\
\hline gloominess & 2 & 3 & 3 \\
\hline sadness & 1 & 2 & 2 \\
\hline rejection & 1 & 1 & 2 \\
\hline boredom & 1 & 2 & 1 \\
\hline anger & 0 & 1 & 2 \\
\hline regret & 0 & 1 & 0 \\
\hline fury & 0 & 1 & 0 \\
\hline disgust & 0 & 0 & 0 \\
\hline
\end{tabular}

Table 4 shows the levels of alertness, which varied between two extremes - maximum alertness and shallow sleep. Most participants reported a state of usual alertness or drowsiness.

Table 4. Levels of alertness during the Vibrobed sessions

\begin{tabular}{cccc}
\hline Levels of alertness & I1 & I2 & I3 \\
\hline maximum alertness & 3 & 1 & 2 \\
\hline usual alertness & 10 & 14 & 14 \\
\hline drowsiness & 18 & 19 & 17 \\
\hline shallow sleep & 4 & 3 & 1 \\
\hline deep sleep & 0 & 0 & 0
\end{tabular}

The results of the qualitative part of the research are based on the analysis of interviews, which focused on the mental associations of the participants. A total of 10 subcategories were created, with only some directly related to the phenomena researched through the questionnaire, i.e. bodily perception, emotions, alertness, etc. (see Appendix 2). Those were, for instance, the subcategories of tension and relaxation, position, movement, vibration, alertness, perception of an activity, a story, etc. Most categories were designed to provide contextual meaning, which helped to gain a deeper understanding of what is happening for the participants during a Vibrobed session (e.g. the subcategory of nature
- the environment, the elements, community experience, animals, musical instruments, colours, and more).

\section{Discussion}

The results of the quantitative part of the study suggest that the Vibrobed program may have a positive effect on physical well-being, which may help reduce muscle tension and induce some additional physical experiences (feeling of warmth, heaviness, energy flow and changes in breathing rhythm). According to some authors and their concepts of relaxation, such physical experiences are characteristic of the relaxed state of the body [29] and are related to the parasympathetic division of the nervous system [30]. In this respect, the findings of the quantitative part of the study coincide with the frequently represented categories created for the analysis of participants' mental associations in the qualitative part. Their associations corresponded to the changing characteristics of music and low-vibrations, as the first half of the recording had a more dynamic rhythm (the corresponding associations were forest penetration, jungle trekking, dancing or doing aerobics and the subcategory of tension / relaxation). The conclusions of the present research seem to suggest that the physical processes of the participants were significantly influenced primarily by the tempo, rhythm and pulsation of the music and vibrations [15].

The results of the part of the study related to the emotional experience of the participants show the prevalence of positive emotions, and changes in the occurrence of emotions in subsequent meetings. It is interesting to compare the values obtained in the different parts of the questionnaire between the individual measurements of each participant. The declining tendency related to some emotions may be explained by the novelty of the situation during the first measurement, which seems applicable especially to the intensity of physical well-being and some other emotions (expectation, curiosity, surprise and astonishment). The increasing tendency may in some cases (e.g. with the emotions of trust and optimism) be related to the development of participants' relationship to this type of therapeutic program during the subsequent measurements, or with the development of a therapeutic relationship [14].

A session on the Vibrobed may cause drowsiness, although the responses related to alertness were relatively varied. This finding may be logically explained by the composition of the vibroacoustic program and must be respected by the practitioners in the process of planning future Vibrobed sessions (e.g. by granting participants enough time after the session).

Considering all obtained quantitative and qualitative data, the following conclusions can be drawn:

- The Vibrobed program enables psychosomatic regulation of the body, which corresponds to the 
initial assumptions regarding the effectiveness of VAT [5]. The Elements 2019, the music recording used in this study, induces physical relaxation and an emotional experience with positive valence. However, the interaction between the pulsation of the low-frequency vibrations and the rhythm and dynamics of the music can also have an activating effect, which manifested itself especially during the first part of the program.

- The vibroacoustic program leads to mental associations which undoubtedly reflect the external stimuli (e.g. the type of vibrations and the character of music), but also the heterogeneity of the intrapsychic content with personal meanings.

- The subjective experience of a Vibrobed session varies depending on the time domain; the initial meetings involved strong emotions related to the novelty of the situation.

Further research should focus on longitudinal monitoring of Vibrobed sessions and their effect on participants' subjective perception in relation to time domain. Moreover, it might be interesting to determine to what extent the subjectively perceived changes are related to the music being listened to and to what extent they are related to the received vibrations. So far, the use of the Vibrobed has mainly been researched as a comprehensive program integrating vibrations and music; the field of VAT research offers a minimal number of studies focusing on the two effective factors in isolation [31, 14].

Based on the results obtained in the study, we suggest that it might be beneficial to perform the Vibrobed program at educational institutions, for instance at universities. Here, VAT could be used to manage students' acute stress, thus improving their overall quality of life. In some clients, vibroacoustic therapy could be combined with other preventive and therapeutic techniques, such as guided imagination or autogenous training. In addition, the results can be beneficial for professionals from various fields, as the therapeutic effect of vibrations and music is used, for example, in physiotherapy and rehabilitation medicine [32].

Due to the pilot nature of this study, it is necessary to recognize its limitations, which may help modify the research methodology in any subsequent studies. The limitations included low number of participants, the method used to select participants (i.e. an intentional selection which did not necessarily correspond with to all characteristics of the basic research sample), the absence of a control group, and the use of a non-standardized questionnaire and measurements scales. To verify the effectiveness of VAT as a preventive program for university students, it would be necessary to modify the methodology and implement a research design of an experimental study. This was already done by authors and a protocol of RCT study was submitted to clinicaltrials.gov (trail registration number NCT04293848). This protocol is focused on university students in acute stress and uses a recording created specifically for stress management (The Elements 2020) so that the findings from the planned project will enable researchers and therapists to suggest more specific therapeutic programs with VAT. On the other hand, the current study brought forth some valuable findings, as the subjective perception of VAT in university students has, up until now, been researched only rarely $[20,33]$.

\section{Conclusions}

The new vibroacoustic technology Vibrobed, along with its listening programs, is characterized by a close interaction between music and low-frequency sound, by sequential dosing of low-frequency sound and by the use of frequency and amplitude modulations. An session on the Vibrobed has the potential to regulate psychosomatic activity of the human body and affect its perception, emotional experience, level of alertness and the accompanying mental associations towards an overall relaxation of the organism. This conclusion, however, needs to be supported by additional experimental studies, ideally using physiological measurement methods. The authors suggest that further research focus on exploring effects of the Vibrobed program on stress management and quality of life of university students.

\section{Acknowledgements}

We are very grateful to Acoustic Brothers, s.r.o. and the Faculty of Education, Palacký University in Olomouc for their support of our research. The project was funded by Palacký University, Faculty of Education, grant number "IGA_PdF_2020_016" titled "The Research of Effectivity of Music Therapy and Positive Behaviour Support in People with Special Needs". 


\section{Appendix 1}

C2) Subjective perception of participant's physical and mental state immediately after a session on the Vibrobed

\section{Physical well-being:}

(Please state the number which expresses your physical well-being on the scale $0-10$, where 0 corresponds to absolute distress and 10 to absolute well-being.)

\section{Mental well-being:}

(Please state the number which expresses your mental well-being on the scale $0-10$, where 0 corresponds to absolute distress and 10 to absolute well-being.

\section{Overall sense of your well-being (physical, mental, social):}

(Please state the number which expresses your overall well-being on the scale $0-10$, where 0 corresponds to absolute distress and 10 to absolute well-being)

\section{Additional comments on the previous questions. Please state only unusual/remarkable experience (for more questions on predictable experience, see below).}

\section{Physical perception}

5a) What is your current perception of the muscle tonus in your body?

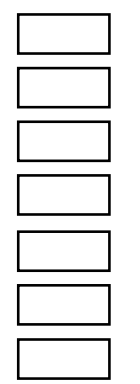

My muscles feel completely relaxed.

My muscles feel a lot more relaxed than before.

My muscles feel somewhat more relaxed than before.

I do not feel any change.

My muscles feel somewhat more tense than before.

My muscles feel a lot more tense than before.

My muscles feel completely tense.

$5 b)$ How are you feeling along your spinal cord?

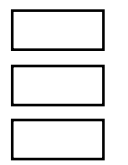

more relaxed

same as before

more tensed

5c) Are you experiencing any unpleasant physical feelings in the region of your head and neck?

$\begin{array}{ll}\square \text { yes } & \text { Please specify: } \\ \square \text { no }\end{array}$

5d) In which OTHER area or areas of your body can you feel specific changes?

Which other specific changes did you feel?

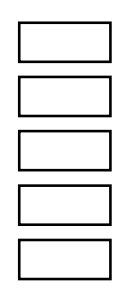

changes of breathing rhythm

feeling noticeable change of heartbeat

sweating

feeling cold

feeling warm 
$\square$ feeling heavy
$\square$ feeling energy flow
$\square$ other (please specify)

6. Mental experiencing

6a) Emotional experiences

Now I am feeling emotionally:

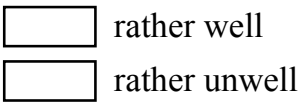

Which emotions arose in you while listening?

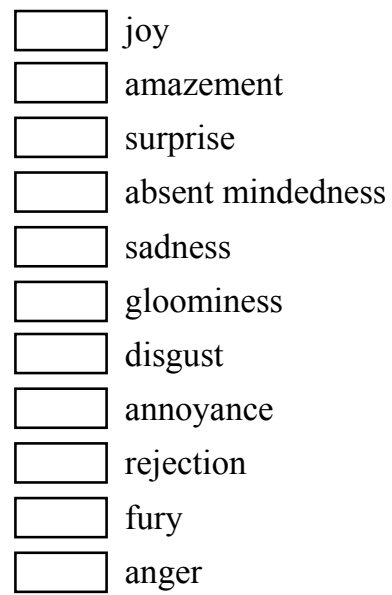

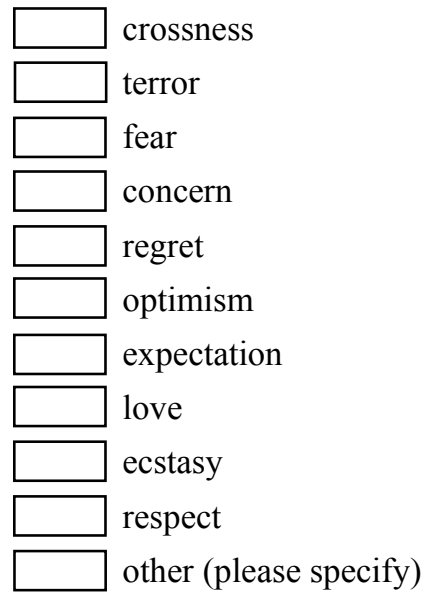

6b) Mental processes

What was the level of your alertness while you listened to the music?

$\square$ maximum alertness
$\square$ usual alertness
$\square$ drowsiness
$\square$ shallow sleep
$\square$ deep sleep

Mental associations:

Please describe any associations, thoughts, images or fantasies that came to you while listening:

\section{Response to the music recording}

How did you like the music recording on the whole?

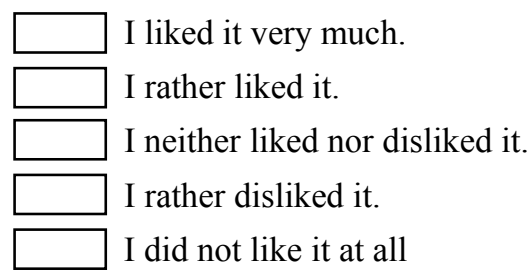


How did you like the individual compositions?

1) Heartbeat.

2) Stimulation

3) Relaxation

4) Atmospheric music

Please add any other comments - you can share anything you wish in relation to this new experience. Optional answers:

\section{AUDIO RECORDING}

Registration code: PARTICIPANT'S NUMBER-NUMBER OF MEETING e.g. 07-1

\section{Appendix 2: Mental Associations Related to Vibrobed Sessions}

\begin{tabular}{|c|c|c|}
\hline Subcategory & Codes & Feedback samples \\
\hline $\begin{array}{l}\text { tension and } \\
\text { relaxation }\end{array}$ & $\begin{array}{l}\text { calming down, switching off, stress relief, } \\
\text { relaxation, feeling dynamic, feeling } \\
\text { peaceful, unwinding, weird sense of } \\
\text { relaxation }\end{array}$ & $\begin{array}{l}\text { "It was a pleasant, relaxing experience, and I'm in a better state now } \\
\text { than before. I didn't expect to feel the vibrations so distinctly." } \\
\text { "Initially, I was afraid of how this was going to affect me, but it turned } \\
\text { out to be a pleasant surprise. I feel mentally relaxed and at peace. The } \\
\text { music was pleasant, too." }\end{array}$ \\
\hline $\begin{array}{l}\text { physical } \\
\text { perception }\end{array}$ & $\begin{array}{l}\text { feeling warm, feeling heartbeat, feeling } \\
\text { dynamic, surplus of energy, strength, } \\
\text { feeling cold, feeling heavy }\end{array}$ & $\begin{array}{r}\text { "It was great to feel the vibrations move around my body." } \\
\text { I got goose bumps in some parts of my body, as the vibrations gradually } \\
\text { reached them." } \\
\text { "The second time it felt nicer. It has energised me, although I already } \\
\text { arrived with a lot of energy. It has relaxed my shoulders and my back." }\end{array}$ \\
\hline location / place & $\begin{array}{l}\text { lying in the grass, lying on a sandy beach, } \\
\text { lying on cracked dry land - being in the } \\
\text { body for a time and then looking at myself } \\
\text { from high above }\end{array}$ & $\begin{array}{c}\text { "It felt nice to leave the world in a way, my thoughts transported me into } \\
\text { a completely different universe, and then I was in Africa for a while." } \\
\text { "I was lying on a sandy beach by the sea and listening to the sounds of } \\
\text { waves." }\end{array}$ \\
\hline movement & $\begin{array}{l}\text { dancing, soaring in the air, flying, fleeing, } \\
\text { being carried away, floating, diving, } \\
\text { swimming, doing aerobics, exercising, } \\
\text { marching, walking, jumping }\end{array}$ & $\begin{array}{c}\text { "I felt as if I was swaying and swinging in different directions." } \\
\text { "When I was listening to the second composition, I felt as if I was } \\
\text { dancing." }\end{array}$ \\
\hline $\begin{array}{l}\text { vibration / wave } \\
\text { motion }\end{array}$ & $\begin{array}{l}\text { pulsation, vibration - oscillating lines, } \\
\text { stimulation, amplitudes, waves, energy } \\
\text { flow (vibrations), pulsating objects, } \\
\text { vibrating cells, moving circles }\end{array}$ & $\begin{array}{c}\text { "I perceived the vibrations as lines oscillating in different ways." } \\
\text { "When the vibrations became stronger, if felt very pleasant, like a sort of } \\
\text { massage." } \\
\text { "I sensed a kind of energy flow." }\end{array}$ \\
\hline alertness/ sleep & $\begin{array}{l}\text { drowsiness, feeling tired, shallow sleep, } \\
\text { alertness, falling asleep }\end{array}$ & $\begin{array}{c}\text { "This time I knew what to expect and felt more relaxed. It was great, I } \\
\text { managed to fall asleep and get some rest." } \\
\text { "I arrived at the session kind of down and a bit absent minded. The } \\
\text { music and the vibrations calmed me down and helped me concentrate } \\
\text { and regulate myself. I was more alert than last time." } \\
\text { "I was kind of out of myself, drowsy, almost asleep." }\end{array}$ \\
\hline emotions & joy, respect, rejection, laughter & $\begin{array}{c}\text { "I felt happiness, joy and desire to help others." } \\
\text { "Today I felt rejection." } \\
\text { "On the whole, my feelings and sensations were pleasant." }\end{array}$ \\
\hline plot / story & $\begin{array}{l}\text { exploring unknown territory, penetrating a } \\
\text { forest, going down the river, two white } \\
\text { figures on a red background - rhythmically } \\
\text { moving, dancing majorettes (when I was } \\
\text { little), waking up in a desert, trekking in the } \\
\text { jungle, I was sitting on top of a cliff, } \\
\text { landing off in a helicopter, laser game, } \\
\text { American Indian burial rites }\end{array}$ & $\begin{array}{l}\text { "The last session seemed more like a fantasy; now I perceive it more as } \\
\text { reality. I imagined a small child, a baby elephant, beginning of a new } \\
\text { life, happiness; but at the same time there was some kind of downslide. } \\
\text { Then I fell asleep." } \\
\text { "I felt as if I was exploring an unknown territory, as if I was penetrating } \\
\text { a forest, and then I floated down the river, as if I was somewhere in the } \\
\text { Amazonian rainforest." }\end{array}$ \\
\hline $\begin{array}{l}\text { non-specific } \\
\text { statements }\end{array}$ & $\begin{array}{l}\text { here and now, no images, trying not to } \\
\text { think, fluctuating thoughts, I don't } \\
\text { remember, I must not fall asleep, just be } \\
\text { and relax, nothing, nothing at all, brain } \\
\text { switched off, emptiness }\end{array}$ & $\begin{array}{c}\text { "I felt relaxed spiritually." } \\
\text { "I felt more here and now." } \\
\text { "I looked forward to lying down and switching off, and not having to } \\
\text { think about anything else today." }\end{array}$ \\
\hline other & $\begin{array}{l}\text { freedom, openness, dreaming, erotic } \\
\text { feelings, well-being, sexual fantasies, } \\
\text { ethereal feelings, feeling well, respect, } \\
\text { rejection, sad past events }\end{array}$ & $\begin{array}{c}\text { "Complete relaxation. I only heard the music and felt the vibrations, not } \\
\text { thinking about anything else at all." }\end{array}$ \\
\hline
\end{tabular}




\section{REFERENCES}

[1] Wigram T. "The Effects of Vibroacoustic Therapy on Clinical and Non-Clinical Populations," Ph.D. Thesis, London University, London, UK, 1996.

[2] Punkanen M., Ala-Ruona E. "Contemporary Vibroacoustic Therapy: Perspectives on Clinical Practice, Research, and Training," Music Med., vol. 2012; no. 4, pp. 128-135, 2012. DOI: $10.1177 / 1943862112445324$

[3] Kantor J., Kantorová L., Marečková J., Peng D., Vilímek Z. "Potential of Vibroacoustic Therapy in Persons with Cerebral Palsy: An Advanced Narrative Review," International Journal of Environmental Research and Public Health, vol. 16, no. 20 , p. 3940,2019 . DOI: $10.3390 /$ ijerph16203940

[4] Accoustic Brothers, s.r.o. "What is Vibrobed", http://www.vibrobed.eu (accessed Nov 1, 2020)

[5] Skille O. "VibroAcoustic Therapy," Journal of Music Therapy, vol. 8, no. 1, pp. 61-77, 1989.

[6] Rüütel E., Vinkel I., Eelmäe P. "The effect of short-term vibroacoustic treatment on spasticity and perceived health condition of patients with spinal cord and brain injuries," Music Medicine, vol. 9, no. 3, pp. 202-208, 2017. DOI: 10.47513/mmd.v9i3.541

[7] Katusic A., Alimovic S., Mejaski-Bosnjak V. "The effect of vibration therapy on spasticity and motor function in children with cerebral palsy: A randomized controlled trial," NeuroRehabilitation vol. 32, no. 1, pp. 1-8, 2013. DOI: 10.3233/NRE-130817

[8] King L., Almeida Q. "The Effects of Sound Wave Vibration Therapy on Motor Symptoms of Parkinson's Disease", http://www.nextwaveworldwide.com/wp-content/uploads/2 013/09/Parkinson.pdf (accessed 24 May, 2020)

[9] Ludqvist L., O., Andersson G., Viding J. "Effects of Vibroacoustic Music on Challenging Behaviors in Individuals with Autism and Developmental Disabilities," Research in Autism Spectrum Disorders, vol. 3 no. 2, pp. 390-400, 2009. DOI: 10.1016/j.rasd.2008.08.005

[10] Delmastro F., Martino F. D., Dolciotti C. "Physiological Impact of Vibro-Acoustic Therapy on Stress and Emotions through Wearable Sensors," 2018 IEEE International Conference on Pervasive Computing and Communications Workshops; pp. 621-626, 2018. DOI: 10.1109/PERCOMW.2018.8480170

[11] Campbell E., A., Hynynen J., Burger B., Vainionpää A. Ala-Ruona E. "Vibroacoustic treatment to improve functioning and ability to work: a multidisciplinary approach to chronic pain rehabilitation," Disability and Rehabilitation, vol. 13, no. Nov, pp. 1-16, 2019. DOI: 10.1080/09638288.2019.1687763

[12] Rüütel E. "The psychophysiological effects of music and vibroacoustic stimulation," Nordic journal of music therapy, vol. 11 , no. 1 , pp. 16-26, 2002. DOI: $10.1080 / 08098130209478039$

[13] Koike Y., Hoshitani M., Tabata Y., Seki K., Nishimura R., Kano Y. "Effects of Vibroacoustic Therapy on Elderly Nursing Home Residents with Depression," Journal of Physical Therapy Science, vol. 24, no. 3, pp. 291-294, 2012. DOI: $10.1589 /$ jpts.24.291.
[14] Campbell E., Burger B., Ala-Ruona E. "A Single-Case, Mixed Methods Study Exploring the Role of Music Listening in Vibroacoustic Treatment," Voices: A World Forum for Music Therapy, vol. 19, no. 2, pp. 27-27, 2019. DOI: 10.15845/voices.v19i2.2556

[15] Brabant O., van de Ree M., Erkkilä J. "The effect of resonance frequency breathing when used as a preparatory exercise in music psychotherapy: A single-case experimental study of a client with anxiety disorder," Arts in Psychotherapy, vol. 56, pp. 7-18, 2017. DOI: 10.1016/j.aip.2017.08.004

[16] Wigram T. "Two experiments to evaluate the sensation of vibration from low frequency tones in the human body," (Chapter 6). The Effects of Vibroacoustic Therapy on Clinical and Non-Clinical Populations. Ph.D. Thesis, London University, London, UK, 1996.

[17] Wigram T. "The measurement of mood and physiological responses to vibroacoustic therapy in nonclinical subjects," In Music vibration and health, $1^{\text {st }}$ ed, Cherry Hill: Jeffrey Books, 1997, pp. 87-98.

[18] Wigram T. "The Effect of Amplitude Modulation of the Pulsed SinusoidaI Low Frequency Tone as a Stimulus in Vibroacoustic Therapy," In Music vibration and health, $1^{\text {st }}$ ed, Cherry Hill: Jeffrey Books, 1997, pp. 133-141.

[19] Brodsky W. "Post-exposure effects of music-generated vibration and whole-body acoustic stimulation among symphony orchestra musicians," Psychology of Music, vol. 28 , no. 1 , pp. 98-115, 2000. DOI: $10.1177 / 0305735600281007$

[20] Ahonen H., Deek P., Kroeker J. "Low Frequency Sound Treatment Promoting Physical and Emotional Relaxation -Qualitative Study," International Journal of Psychosocial Rehabilitation, vol. 17, no. 1, pp. 45-58, 2012.

[21] Beiter R., Nash R., McCrady M., Rhoades D., Linscomb M., Claraham M., Sammut S.. "The prevalence and correlates of depression, anxiety, and stress in a sample of college students," Journal of Affective Disorders, vol. 173, no. 1, pp. 90-96, 2015. DOI: 10.1016/j.jad.2014.10.054

[22] Hsieh H. F., Shannon S. E. "Three Approaches to Qualitative Content Analysis," Qualitative Health Research, vol. 15, no. 9, pp. 1277-1288, 2005. DOI: 10.1177/1049732305276687

[23] Tesch R. "Qualitative research: Analysis Types and Software Tools", $1^{\text {st }}$ ed., New York: Falmer, 1990, pp. 1-330.

[24] Bradberry T., Greaves J. "Emoční inteligence", $1^{\text {st }}$ ed, Brno: BizBooks, 2013, pp. 1-240.

[25] Ekman P. "Odhalené emoce: naučte se rozpoznávat výrazy tváŕe a pocity druhých", $1^{\text {st }}$ ed, Brno: Jan Melvil Pub, 2015, pp. 1-328.

[26] Goleman D. "Emoční inteligence: proč může být emoční inteligence důležitější než IQ", $1^{\text {st }}$ ed, Praha: Columbus, 1997, pp. 1-336.

[27] Keleman S. "Anatomie emocí: struktury lidské zkušenosti", $2^{\text {nd }}$ ed, Praha: Portál, 2013, pp. 1-216.

[28] Nakonečný M. "Lidské emoce", $1^{\text {st }}$ ed, Praha: Academia, 2000, pp. 1-501. 
[29] Schultz J. H. "Autogenní trénink", $1^{\text {st }}$ ed, Poznání, 2019, pp. $1-87$.

[30] Spintge R. "Musikmedizinische Interventionen in der klinischen Medizin bei Schmerz, Angst und Stress" In Bernatzky G., Kreutz G. (eds.) Musik und Medizin, $1^{\text {st }}$ ed, Springer: Vienna, 2015, pp. 71-83, DOI: 10.1007/978-3-7091-1599-2_6

[31] Naghdi L., Ahonen H., Macario P., Bartel, L. "The effect of low-frequency sound stimulation on patients with fibromyalgia: A clinical study," Pain research \& management, vo. 20, no. 1, pp. e21-e27, 2015. DOI: $10.1155 / 2015 / 375174$

[32] Smékal D., Bednáříková H., Měrková H., Bohuslavová M. "The influence of the regional focal vibration on patients with nonspecific chronic pain in the lumbar spine," Rehabilitacia, vo. 51, no. 3, pp. 131-137, 2014.

[33] Rüütel E. "Sociocultural context of body dissatisfaction and possibilities of vibroacoustic therapy in diminishing body dissatisfaction," Ph.D. Thesis, Tallinna Pedagoogikaülikooli Kirjastus, Tallinn, Estonia, 2004. 